\title{
Reproductive Characteristics of Wild Female Phayre's Leaf Monkeys
}

\author{
AMY LU ${ }^{1,2 *}$, CAROLA BORRIES ${ }^{3}$, NANCY M. CZEKALA ${ }^{4}$, AND JACINTA C. BEEHNER ${ }^{2,5}$ \\ ${ }_{1}^{1}$ Interdepartmental Doctoral Program in Anthropological Sciences, Stony Brook University, Stony Brook, New York \\ ${ }^{2}$ Department of Psychology, University of Michigan, Ann Arbor, Michigan \\ ${ }^{3}$ Department of Anthropology, Stony Brook University, Stony Brook, New York \\ ${ }^{4}$ Papoose Conservation Wildlife Foundation, Del Mar, California \\ ${ }^{5}$ Department of Anthropology, University of Michigan, Ann Arbor, Michigan
}

Understanding female reproductive characteristics is important for assessing fertility, interpreting female behavior, and designing appropriate conservation and captive management plans. In primate species lacking morphological signs of receptivity, such as most colobines, determination of reproductive parameters depends on the analysis of reproductive hormones. Here, we use fecal hormone analysis to characterize cycle patterns $(N=6$ females) and gestation length $(N=7$ females $)$ in a group of wild Phayre's leaf monkeys (Trachypithecus phayrei crepusculus) in Phu Khieo Wildlife Sanctuary, Thailand. We found that both fecal estrogen (fE) and progestin (fP) levels showed clear biological patterns indicative of ovulation and conception. However, because fP patterns were inadequate in determining the end of the luteal phase, we used $\mathrm{fE}$ rather than $\mathrm{fP}$ patterns to delineate menstrual cycle parameters. We found a mean cycle length of 28.4 days $(N=10)$, with follicular and luteal phases of $15.4(N=10)$ and 12.5 days $(N=14)$, respectively. On average, females underwent 3.57 $(N=7)$ cycles until conception. Average gestation length was 205.3 days $(N=7)$, with fE levels increasing over the course of pregnancy. Overall, the reproductive characteristics found for Phayre's leaf monkeys were consistent with results for other colobine species, suggesting that fecal hormone monitoring, particularly for $\mathrm{fE}$ metabolites, can provide useful reproductive information for this species. Am. J. Primatol. 72:1073-1081, 2010. (1) 2010 Wiley-Liss, Inc.

Key words: cycle length; fecal hormones; follicular phase; gestation; luteal phase

\section{INTRODUCTION}

Noninvasive measurement of ovarian hormones in wild primates provides basic information on reproductive parameters, such as cycle length and gestation [e.g. Brachyteles arachnoides: Strier \& Ziegler, 1997; Colobus guereza: Harris \& Monfort, 2006; Eulemur fulvus: Ostner \& Heistermann, 2003; Pan troglodytes: Emery \& Whitten, 2003; Papio cynocephalus: Beehner et al., 2006]. Knowledge of such characteristics is important for assessing fertility, understanding female behavior [Maestripieri, 1999; Ramirez et al., 2004], and sexual strategies [e.g. Deschner et al., 2004; Engelhardt et al., 2007], and examining differences in life history strategies within [e.g. Borries et al., 2001] and across species [Barnett \& Abbott, 2003; Harvey et al., 1987; Martin \& MacLarnon, 1985]. Furthermore, acquiring a fundamental understanding of female reproductive physiology is one of the first steps toward developing effective management and conservation plans [Cockrem, 2005].

Although estrogen and progesterone metabolites are routinely monitored across many cercopithecoid species, including several species of macaques [Macaca fascicularis: Engelhardt et al., 2005;
M. fuscata: Fujita et al., 2004; M. sylvanus: Brauch et al., 2007; Möhle et al., 2005; M. tonkeana: Aujard et al., 1998] and baboons [Papio anubis: Higham et al., 2008a; P. cynocephalus: Beehner et al., 2006; Gesquiere et al., 2007], comparatively fewer studies have examined wild colobines [but see: C. guereza: Harris \& Monfort, 2006; Semnopithecus entellus: Ziegler et al., 2000]. However, because most colobines have no conspicuous visual signs of receptivity, such as sex skin swellings [Nunn, 1999], it is surprising that few studies have utilized this tool for documenting colobine reproduction. Furthermore, because primate sexual behavior commonly

Contract grant sponsor: National Science Foundation; Contract grant numbers: BCS-0542035; BCS-0452635; Contract grant sponsors: The Leakey Foundation; The American Society of Primatologists; The Zoological Society of San Diego; The University of Michigan.

*Correspondence to: Amy Lu, Department of Psychology, University of Michigan, 3469 East Hall, 530 Church St., Ann Arbor, MI 48109-1043. E-mail: luamy@umich.edu

Received 14 April 2010; revised 21 June 2010; revision accepted 25 June 2010

DOI 10.1002/ajp.20866

Published online 30 July 2010 in Wiley Online Library (wiley onlinelibrary.com). 
occurs outside of the periovulatory phase [Wallen, 2001], estimates of reproductive characteristics based solely on behavior are often less precise than those based on hormones.

In this study, we analyze fecal estrogen (fE) and progesterone (fP) metabolites to examine female reproductive characteristics in a wild group of Phayre's leaf monkeys (Trachypithecus phayrei crepusculus) in Phu Khieo Wildlife Sanctuary, Thailand. Our specific goals are: (1) to validate the use of $\mathrm{fE}$ and $\mathrm{fP}$ metabolites to assess reproductive parameters in Phayre's leaf monkeys, (2) to determine cycle length (including follicular and luteal phase) and gestation length in this species, and (3) to compare these reproductive characteristics to other primates, particularly colobines and cercopithecines.

\section{METHODS}

\section{Subjects and Study Period}

The data for this study come from a population of wild Phayre's leaf monkeys from Phu Khieo Wildlife Sanctuary, Thailand $\left(16^{\circ} 5^{\prime}-35^{\prime} \mathrm{N}, 101^{\circ} 20^{\prime}-\right.$ $55^{\prime} \mathrm{E}$, Chaiyaphum Province, elevation: $300-1,300 \mathrm{~m}$ above sea level). Phayre's leaf monkeys live in groups containing 1-5 adult males and 2-12 adult females [Borries \& Koenig, unpublished data]. Mating is promiscuous. Although births can occur in all months of the year, most births were recorded between November and April [Borries et al., in review]. The interbirth interval after a surviving offspring is close to 2 years [Borries et al., 2008].

This research was conducted as part of a longterm project (directed by A. Koenig and C. Borries), which began in October 2000. Data collected and analyzed for this study comprise a 20 -month period from February 2005 to September 2006 and derive from one particular study group, PB. This group has been habituated since 2004, and demographic data are available since June 2003 [Borries \& Koenig, unpublished data]. The group contained 11 adult females at the start of the study; however, one female emigrated shortly after the study commenced and we focused on the 10 remaining females. All females were multiparous. Although absolute ages for females were unknown, relative estimates based on skin wrinkling, color of eye lens, and nipple length [Hrdy, 1977] indicate that most females $(N=8)$ were either young or prime adults, and two females were beyond prime.

\section{Fecal Hormone Collection}

Fecal samples were collected opportunistically from all ten adult females across the study. However, data collection was not distributed equally across time or across females. From February to December 2005 , we collected monthly fecal samples from all ten females for broad estimates of reproductive state.
Once the first mating was observed (December 13, 2005), we increased our rate of collection to neardaily for any mating female (assumed to be cycling) to facilitate later estimates of ovulation and conception. During the first 2 weeks after the start of mating, we collected daily samples from the two cycling females that mated first. From January 1, 2006, we sampled all females expected to resume cycling (based on their earlier date of birth and the mean interbirth interval). One additional female was added toward the end of the study period because she unexpectedly began to mate. Collection frequency for cycling females $(N=7)$ was $24.28 \pm 0.53$ $\mathrm{SE} \quad$ samples/female/month $\quad$ (range $=15-3$, total samples $=1,464)$. These samples formed the basis of our analysis of cycling patterns, gestation length, and hormone patterns in the first few months of pregnancy. In addition, a select number (mean $=$ $35.8 \pm 1.30 \mathrm{SE}$ samples/female, range $=25-42 ;$ total $=143$ samples from four pregnancies) of samples from 2005 were used only to construct cross-sectional hormonal profiles for pregnant females covering the entire length of gestation.

Entire fecal samples were collected in $30 \mathrm{ml}$ plastic vials (Sarstedt, Newton, NC: vial $\# 75.1337 .500$, lid \#76.1340.560), kept on ice in the field, and frozen $\left(-20^{\circ} \mathrm{C}\right)$ upon return to the field station (within $2-13 \mathrm{hr}$ ). Samples remained frozen until they were shipped on ice to the Conservation and Research of Endangered Species center at the Zoological Society of San Diego.

\section{Fecal Hormone Analysis}

Samples were first lyophilized and sifted through mesh wire $(16 \times 16$ mesh; McMaster-Carr, Robbinsville, NJ: \# 9223T82) to remove vegetative matter and then transported on dry ice to the Core Assay Facility in the Department of Psychology at the University of Michigan for further analyses. Hormone extraction protocols followed Wasser et al. [1994]. In brief, a $0.1 \mathrm{~g}$ portion of each sample was added to $95 \% \mathrm{EtOH}$ in $8 \mathrm{ml}$ plastic test tubes (Sarstedt: \#60.542.007). The tubes were then vortexed for $1 \mathrm{~min}$, boiled in a water bath $\left(90^{\circ} \mathrm{C}\right)$ for $20 \mathrm{~min}$, and centrifuged at $1,500 \mathrm{rpm}$ for an additional 20 min. After centrifugation, the supernatant was decanted into $16 \times 100 \mathrm{~mm}$ test tubes (Fisher, Pittsburgh, PA: \#14-961-29). This process was repeated twice. The fecal matter was then discarded and the supernatant was dried down under nitrogen gas. Extracted samples were reconstituted in $100 \% \mathrm{EtOH}$, transferred into $2 \mathrm{ml}$ microcentrifuge tubes (Sarstedt: \#72.694.007), and stored at $-20^{\circ} \mathrm{C}$ until analysis. Extraction of radiolabeled progesterone and estrogen yielded recoveries of $86.7 \pm 3.8 \%(N=10)$ and $91.5 \pm 0.8 \%(N=10)$, respectively. All fecal hormone metabolites were analyzed using radioimmunoassay (RIA).

Fecal progestins were assessed utilizing a progesterone primary antibody (CL425: C. Munro, UC, 
Davis) diluted 1:12,000, coupled with commercial progesterone tracer and standards (Pantex, Santa Monica, CA: \#137 TRA, \#137 CAL, \#137 CALO), and a secondary antibody (Goat Anti-mouse IgG, Equitech Bio, Kerrville, TX: \#GAMG-0100). The CL 425 antibody is a monoclonal antibody raised against 4-Pregnen-3 $\alpha$-ol-20-dione (P4) hemisuccinate:bovine serum albumin [Grieger et al., 1990]. It is known to cross-react with a variety of progesterone metabolites [e.g. 4-Pregnen-3 $\alpha$-ol-20-one: $188 \%$; $5 \alpha$-Pregnan33-ol-20-one: $94 \%$; pregnanediol: $<0.1 \%$; see Graham et al., 2001], and has been successfully applied to study fecal progestins in a variety of mammals [e.g. Graham et al., 2001; North \& Harder, 2008]. For a complete protocol, see the following link (http:// www.princeton.edu/ baboon/publications/Altmann lab_protocols_Jan08.pdf). Fecal estrogen metabolites were assessed using a commercial estradiol (E2) RIA kit (MP Biomedicals, Solon, OH: $\# 07138102$ ). Kit instructions were followed with one modificationall reagents were halved from the amount suggested by the manufacturer. Halving all reagents effectively maximizes the amount of samples run per commercial kit without changing assay performance. The E2 antibody was raised against 6-keto-estradiol-17 $\beta$ oxime-BSA, and has minor cross-reactivities with other estrogen metabolites (estrone: 20\%; estriol: 1.5\%; estradiol-17 $\alpha$ : $0.7 \%$ ). Samples were diluted (progesterone: 1:16-1:100; estrogen: 1:8-1:100) in standard zero buffer for analysis. All hormone values are reported as $\mu \mathrm{g} / \mathrm{g}$ or $\mathrm{ng} / \mathrm{g}$ dry feces.

Both assays yielded dose-response curves parallel to the standard curve, and accuracy tests found recoveries of $104.1 \pm 4.4 \%(N=8)$ for progestins and $90.2 \pm 10.0 \%(N=6)$ for estrogens. Assay sensitivity was $31.25 \mathrm{pg} /$ tube $(6.25 \mathrm{ng} / \mathrm{ml})$ for progestins and $0.125 \mathrm{pg} /$ tube $(5 \mathrm{pg} / \mathrm{ml})$ for estrogens, and intra-assay CVs for the high and low fecal pools were 2.8 and $7.2 \%$ for progestins and 6.2 and $1.7 \%$ for estrogens. Finally, inter-assay CVs for high and low fecal pools were 9.9 and $16.3 \%$ for progestins and 6.0 and $10.6 \%$ for estrogens.

\section{Defining Cycle Parameters}

Because ovulation generally occurs after a sharp rise in estrogen (estradiol) and before a gradual rise in progesterone, either or both hormones have been commonly used to delineate cycle length in primates [e.g. days between subsequent estrogen peaks: Higham et al., 2008b, 2009; Yan \& Jiang, 2006; or progesterone rises: Engelhardt et al., 2005; Heistermann et al., 1995]. By contrast, because the corpus luteum scretes progesterone for the duration of the luteal phase, the rise and fall of progesterone has been the easiest marker used to assess the different phases (follicular and luteal) of the menstrual cycle [e.g. Heistermann et al., 1995]. Some studies have also used the beginning of menses [Molskness et al., 2007;
Shimizu et al., 2003] or the rise in estrogen levels from its post-ovulatory nadir [e.g. Emery \& Whitten, 2003] to mark the beginning of the follicular phase. Furthermore, because the periovulatory peak in estrogen levels is followed shortly by ovulation and a rise in progesterone, estrogen patterns can also be used to delineate the beginning of the luteal phase.

To estimate the component phases of the menstrual cycle for Phayre's leaf monkeys, we use $\mathrm{fE}$ rather than $\mathrm{fP}$ patterns, because analysis of $\mathrm{fP}$ data during the putative luteal phase suggest that the fP drop is an inadequate estimate of the end of the luteal phase. Eighty-one percent (13 of 16) of $\mathrm{fE}$ peaks outside the high progestin period showed expected post-ovulatory increases in $\mathrm{fP}$ (i.e. +2.5 SD above baseline) 0-2 days after the fE peak. In two cases, $\mathrm{fP}$ and $\mathrm{fE}$ continued to rise, indicating conception. Hence, fP levels seemed useful for identifying both the beginning of the luteal phase as well as conception. However, following nonconceptive ovulations, fP levels remained elevated for only $7.0 \pm$ SE 0.6 days $(N=10$; median $=7.0$; range: $3-10)$, suggesting that the fall in $\mathrm{fP}$ levels does not mark the end of the luteal phase [the luteal phase for related species are around 11-15 days: $\mathrm{He}$ et al., 2001; Heistermann et al., 2001b, 2004; see also discussion below].

To construct composite hormone profiles across the menstrual cycle, we used daily values of $\mathrm{fE}$ and fP (or mean daily values when more than one sample/female was available). These profiles allowed us to identify $25 \mathrm{fE}$ peaks, of which 24 were characterized by adequate sampling (every other day) near the day of the peak to assign a day of ovulation. For one additional peak (with a 3-day sampling gap), we estimated the day of the $\mathrm{fE}$ peak based on trends in the rise and fall of $\mathrm{fE}$ levels, using the $\mathrm{fP}$ values for confirmation. Of the total $25 \mathrm{fE}$ peaks, 9 occurred during a period of plant-related elevation in fP levels ["high progestin period"; Lu et al., in review], likely owing to the consumption of Vitex. An additional $\mathrm{fE}$ peak occurred at the boundary of the "normal period" and the "high progestin period." Because earlier studies (including one on the target females in this study) have suggested that plant-based progestins might influence reproductive function [Garey, 1991; Higham et al., 2007; Lu et al., in review], we restricted our analysis to the $17 \mathrm{fE}$ peaks from 6 females occurring outside $(N=16 \mathrm{fE}$ peaks $)$ or at the boundary $(N=1$ $\mathrm{fE}$ peak) of the high progestin period for estimates of cycling parameters.

We assumed that $\mathrm{fE}$ peaks were representative of ovulations because they were regularly followed by a clear rise in fP levels (see above). However, because gut passage and metabolism usually delays the appearance of hormones in fecal matter from hours to days [Bahr et al., 2000; Perez et al., 1988; Wasser 
et al., 1994], we defined the day before the $\mathrm{fE}$ peak as the day of ovulation. We based this $24 \mathrm{hr}$ correction on observations that fecal glucocorticoids of a related species [Trachypithecus obscurus: Lu \& Czekala, unpublished data] were excreted within $24 \mathrm{hr}$ of an ACTH challenge. Although it is possible that the metabolism of reproductive hormones might be longer than that of glucocorticoids, some studies show that they are similar [e.g. chimpanzees: Emery \& Whitten 2003]. Hence, we conservatively estimated the lag time to be $24 \mathrm{hr}$, thus deviating from the definition used by other researchers [e.g. Engelhardt et al., 2005; Heistermann et al., 2001b; but see Emery \& Whitten, 2003].

Note that our definition of ovulation assumes that estradiol peaks are sufficient to initiate ovulation. An insufficient estradiol rise during the follicular phase may fail to induce a surge in luteinizing hormone, thus leading to an anovulatory cycle with no formation of the corpus luteum and (importantly) no normal rise in progesterone [Dailey \& Neill, 1981; Johnson, 2007]. In this study, the majority $(81.3 \%)$ of ovulations before the high progestin period were characterized by an $\mathrm{fP}$ rise following the $\mathrm{fE}$ peak. Although the remaining three cycles were irregular (i.e. longer), they were characterized by $\mathrm{fP}$ rises before and following the $\mathrm{fE}$ peak, suggesting some degree of function by the corpus luteum. We are therefore confident that peak estrogen levels in the cycles analyzed for this study were sufficient for ovulation and can be used as an accurate marker for designating menstrual cycle parameters.

Hereafter, we will refer to the day of the $\mathrm{fE}$ peak as Day 0. Thus, 1 day before the $\mathrm{fE}$ peak (day of ovulation) is Day -1 , one day after the peak is Day 1 , and so forth. All days were assigned post hoc once hormone data were available. Cycle length $(N=10$ after elimination of an outlier) was defined as the time period from Day 0 ( $\mathrm{fE}$ peak) until the next Day -1 (period between concurrent $\mathrm{fE}$ peaks, with all but the first and last peaks for each female used as indicators of both cycle initiators and terminators). The luteal phase $(N=14)$ was calculated as the number of days from Day 1 to the day before the next $\mathrm{fE}$ rise from its post ovulatory nadir [Fig. 1; see Emery \& Whitten, 2003]. We assumed that the rise in $\mathrm{fE}$ from its nadir $(+2 \mathrm{SD}$ above the preceding three values) indicates the beginning of follicular development. Similarly, the follicular phase $(N=10)$ was calculated as the first day of the fE rise, to the day of the next fE peak (Day 0).

\section{Defining Conception and Pregnancy}

Conceptive cycles were defined as all cycles where post ovulatory fE levels exhibited a sustained increase above follicular levels. In such cases, the conceptive date was defined as the day of ovulation

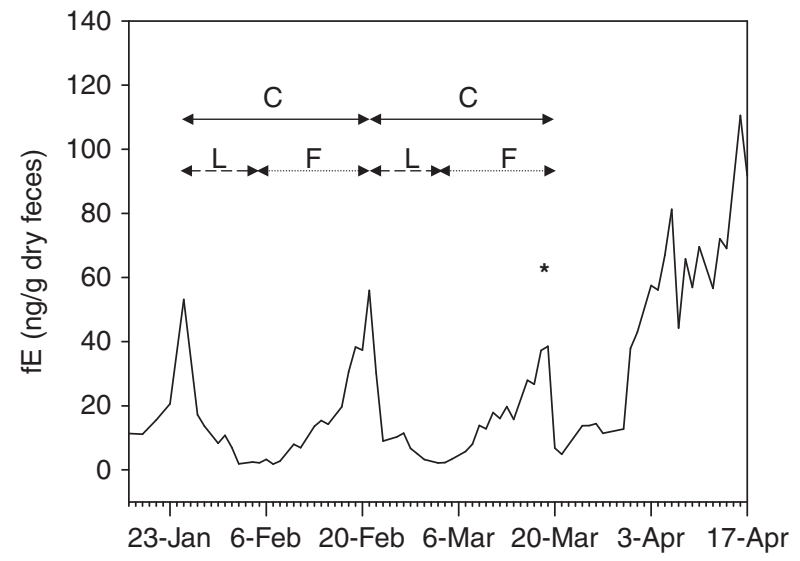

Fig. 1. Representative hormonal profile of one female, showing the use of $\mathrm{fE}$ (ng/g dry feces) patterns to delineate reproductive characteristics $(C=$ cycle length; $F=$ follicular phase; $L=$ luteal phase; ${ }^{*}=$ conception). Major $\mathrm{x}$-axis markers represent successive 2 -week periods.

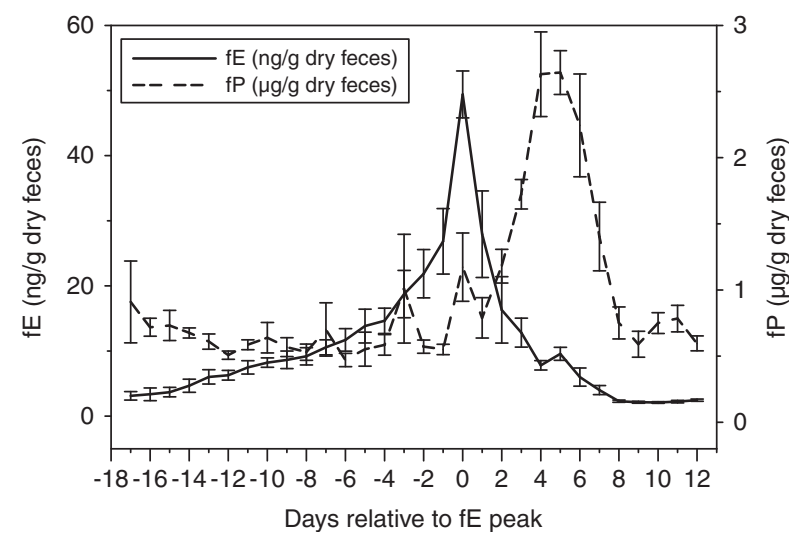

Fig. 2. Composite cycle profile for nine nonconceptive cycles $(N=6$ females). Solid line $=\mathrm{fE}(\mathrm{ng} / \mathrm{g}$ dry feces); dotted line $=\mathrm{fP}$ $(\mu \mathrm{g} / \mathrm{g}$ dry feces $)$; error bars $= \pm \mathrm{SE}$.

(Day -1$)$ for that cycle. Gestation length $(N=7)$ was estimated as the number of days from Day -1 to the day of parturition (from demographic records), and was only assessed for females who were followed consistently in 2006 and for which daily samples allowed estimates of conception. In several cases (six of seven gestations), the group was not followed continuously around birth (mean $=3.9 \pm 1.5$ SE days between follows, range $=3-12$ days), and the day of birth was estimated based on the median day of the period of time between the last group follow and the day when the infant was detected.

Because all pregnancies overlapped with the high progestin period, we used fE profiles (rather than fP profiles) to document changes in hormone levels across pregnancy. To evaluate fE patterns in the beginning of the pregnancy, we used post conceptive weekly hormone averages of six pregnancies ( $N=7$ for first 3 weeks following conception) and compared these values to both periovulatory peak $\mathrm{fE}$ 
levels and follicular mean $\mathrm{fE}$ levels prior to the peak. To examine variation in $\mathrm{fE}$ levels across pregnancy, we compared female fE means across trimesters. This dataset included four pregnancies from 2005 and seven pregnancies from 2006. Because conception dates were unavailable for the four pregnancies from 2005, we estimated conception dates based on the dates of birth and our mean gestation length and then calculated trimester means. Complete pregnancies were only available for 4 of the 11 total pregnancies sampled. Thus, composite hormone profiles for the entire gestation period were constructed from a mixed longitudinal and crosssectional dataset $(N=1-11$ pregnancies per week, with lower sample sizes later in gestation).

\section{Data Analysis}

Because sample sizes were small, statistical tests for cycling and pregnancy parameters were conducted using nonparametric statistics [SPSS, Chicago, IL, Version 16], with reproductive parameters (e.g. cycle length) rather than female, as the unit of analysis. Differences in hormone values between trimesters were assessed using KruskalWallis and Mann-Whitney $U$ tests. Differences in $\mathrm{fE}$ levels between the initial weeks post conception and the cycling periods were assessed using Wilcoxon Signed Ranks Tests because paired samples from the same female were available. Significance is reported at $\alpha=0.05$ level. Bonferroni-Holm corrections were made for all post hoc analyses [Holm, 1979]. Outlier analyses were conducted using Dixon's calculations [Dixon \& Massey, 1969; Sokal \& Rohlf, 1995].

\section{Research Ethics}

All research methods were accepted by the IACUC committee at Stony Brook University and adhered to both the laws of Thailand and the American Society of Primatologists' principles for the ethical treatment of nonhuman primates.

\section{RESULTS}

\section{Menstrual Cycle Parameters}

After eliminating one outlier for cycle length [value $=59$ days, $r_{11}=0.75, \alpha=0.05$, Dixon's Outlier Analysis; Dixon \& Massey, 1969; Sokal \& Rohlf, 1995] and one for follicular phase (value $=44$ days, $r_{11}=0.81$ ), we found an average cycle length of $28.4 \pm \mathrm{SE} 1.6$ days $(N=10$, median $=27.5$ days, range: 21-40 days, Fig. 2), a follicular phase of $15.4 \pm \mathrm{SE} 1.3$ days (follicular phase: $N=10$, median $=15.0$ days, range: $12-26$ days), and a luteal phase of $12.5 \pm \mathrm{SE} 0.4$ days $(N=14$, median $=12$, range: 11-17). During the follicular phase, fE levels averaged $11.74 \pm \mathrm{SE} 1.03 \mathrm{ng} / \mathrm{g}$ dry feces $(N=10)$, reaching peak values of $46.45 \pm \mathrm{SE} 1.74 \mathrm{ng} / \mathrm{g}$ dry feces $(N=15)$ before ovulation, and falling to a nadir during the luteal phase of $6.34 \pm \mathrm{SE} 0.48 \mathrm{ng} / \mathrm{g}$ dry feces $(N=14)$.

\section{Conception and Gestation}

Female Phayre's leaf monkeys experienced 3.57 cycles to conception $( \pm \mathrm{SE} 0.43 ; N=7$, median $=3.0$, range: 2-5). Conception was detected when $\mathrm{fE}$ levels maintained a steady rise 1 week after the $\mathrm{fE}$ peak (Fig. 3). However, weekly fE levels following conception were not significantly different $(N=7$, Wilcoxon Signed Ranks Test: $z=-2.37 ; P=0.0)$ from follicular levels (mean $=12.83 \pm \mathrm{SE} 1.26 \mathrm{ng} / \mathrm{g}$ dry feces) until the 3 rd week of pregnancy (mean $=47.43 \pm \mathrm{SE}$ $2.65 \mathrm{ng} / \mathrm{g}$ dry feces). Furthermore, although fE levels during weeks $3-5$ of pregnancy were above periovulatory peak levels $(N=6$; mean $=48.96 \pm \mathrm{SE} 2.37 \mathrm{ng} / \mathrm{g}$ dry feces), they did not consistently remain above these levels until after the 9th week of gestation $(N=6 ; \quad$ mean $=79.94 \pm \mathrm{SE} \quad 12.56 \mathrm{ng} / \mathrm{g}$ dry feces; Wilcoxon Signed Ranks Test: $z=-2.20, P=0.03$ ).

Mean gestation length was 205.3 days $( \pm$ SE 1.4 days; $N=7$; median $=204.0$; range: $201-211)$. Fecal estrogen levels were significantly different across trimesters (Kruskal-Wallis Test: $H=21.50, \mathrm{df}=2$, $P<0.001$ ), increasing nearly 10 -fold from the first $(N=11 ;$ mean $=59.94 \pm \mathrm{SE} 4.83 \mathrm{ng} / \mathrm{g}$ dry feces $)$ to second trimesters $(N=10$; mean $=535.45 \pm \mathrm{SE} 72.64 / \mathrm{g}$ dry feces; Mann-Whitney $U$ Test: $z=-3.87$, $P<0.0001$ ), with an additional 2-fold increase from the second to third trimesters (Fig. 4; $N=6$; mean $=1,106.78 \pm \mathrm{SE} 132.31 \mathrm{ng} / \mathrm{g}$ dry feces; MannWhitney $U$ Test: $z=-2.71, P=0.007)$. Post parturition samples were only available from the four pregnancies sampled in 2005 . We therefore did not have a large enough sample size to statistically

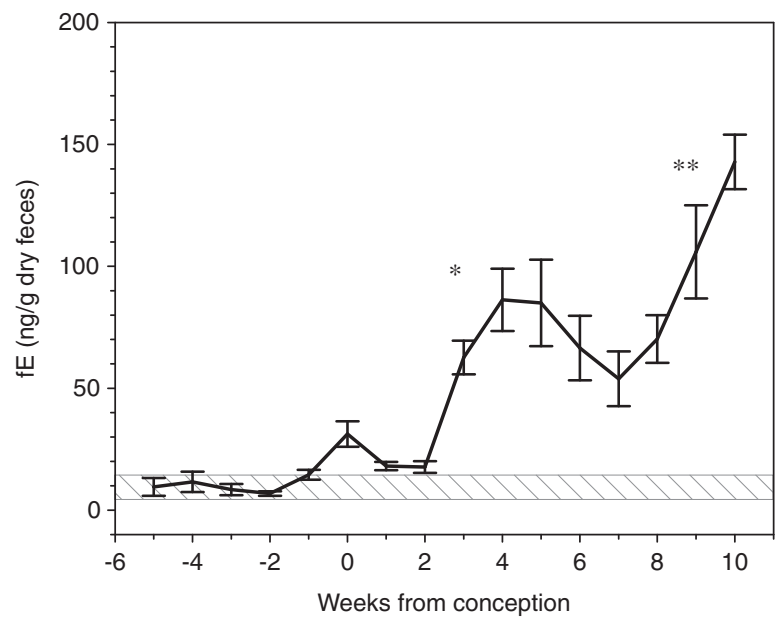

Fig. 3. Composite $\mathrm{fE}(\mathrm{ng} / \mathrm{g}$ dry feces) profile from the 5 weeks before conception through the first 10 weeks of pregnancy $(N=7$ conceptions). Hatched area $=$ mean $\pm \mathrm{SE}$ follicular $\mathrm{fE}$ levels; * = week at which $\mathrm{fE}$ levels are significantly different from follicular $\mathrm{fE}$ levels, ** = week at which $\mathrm{fE}$ levels remain statistically different from peak periovulatory fE levels (Wilcoxon Signed Ranks Test, $\alpha=0.05$ ). 


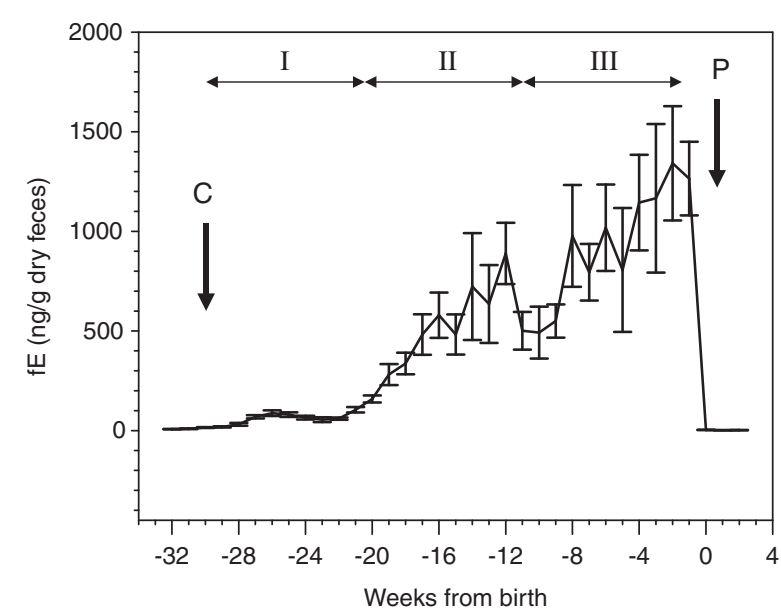

Fig. 4. Composite fE (ng/g dry feces) profile across the gestation period $(N=11)$. Data are derived from a mixed longitudinal and cross-sectional dataset $(C=$ conception, approximately 29.2 weeks (205 days) before birth; $P=$ parturition; $I=$ first trimester; II = second trimester; III = third trimester)

evaluate differences between hormone levels during late pregnancy and those following parturition. However, data from these four pregnancies do show that $\mathrm{fE}$ levels during the first 3 weeks following birth (Fig. $4 ; N=4$; mean $=1.78 \pm$ SE $0.41 \mathrm{ng} / \mathrm{g}$ dry feces) dropped from pregnancy levels to follicular $\mathrm{fE}$ levels.

\section{DISCUSSION}

Here, we present the first data on the reproductive physiology of Phayre's leaf monkeys using noninvasive techniques to monitor steroid metabolites in a wild population. Across a female's menstrual cycle and through pregnancy, fE levels showed clear, consistent cycling peaks related to periovulatory estrogen surges, as well as a gradual rise throughout pregnancy. However, because pregnancy $\mathrm{fE}$ levels did not increase significantly above periovulatory peak levels until the 9 th week of gestation, hormonal sampling during the first trimester alone may not be sufficient to identify pregnancy.

Fecal progestin patterns also provided biologically relevant information on the reproductive physiology of this species. For the majority of cycles, $\mathrm{fP}$ patterns demarcated the beginning of the luteal phase as well as the date of conception. However, $\mathrm{fP}$ patterns alone were inadequate for determining the end of the luteal phase. One possible explanation might be that $T$. phayrei excretes multiple progesterone metabolites, and that the antibody employed in this study failed to detect one of the major ones associated with corpus luteum function toward the end of the luteal phase. In Douc langurs [Pygathrix nemaeus: Heistermann et al., 2004] and long-tailed macaques $[M$. fascicularis: Heistermann et al., 2001a], high performance liquid chromatography
(HPLC) studies have suggested that $5 \alpha$-reduced 20-oxo pregnanes are major fecal metabolites of these species, indicating perhaps that a groupspecific antibody may be more successful (compared with the antibody employed in this study) at capturing hormonal patterns of ovarian function in T. phayrei as well. Future work, comparing multiple antibodies in relation to HPLC and/or radioinfusion studies [e.g. Wasser et al., 2000], will help resolve this matter.

The major impediment to using $\mathrm{fP}$ patterns to document reproductive function in this population was the occurrence of a seasonal increase in progesterone levels, likely owing to the consumption of phytoprogestins [Lu et al., in review]. Similar patterns resulting from phytoprogestin consumption have recently been found in wild populations of chimpanzees [Emery Thompson et al., 2008] and baboons [Higham et al., 2007], suggesting that the consumption of plant steroids may, at times, impede proper interpretation of reproductive state, conception, and cycle parameters from excreted steroid metabolites alone. Although this complication clearly impacts the detection of fP in this population, similar difficulties may pertain to the measurement of $\mathrm{fE}$ in other populations.

Our reported average of 3.57 cycles to conception is high compared with another wild colobine, Hanuman langurs [S. entellus: 1.88 cycles to conception, Ziegler et al., 2000]. This is not surprising, because Hanuman langurs at that site (Ramnagar) are stricter in their birth seasonality [births occur only 6 months out of the year: Koenig et al., 1997]. In this respect, the number of cycles to conception in Phayre's leaf monkeys may be more similar to that of some populations of baboons which give birth yearround, but still show birth peaks during certain months of the year [Alberts et al., 2005; Beehner, 2003; Bentley-Condit \& Smith, 1997; Smuts \& Nicolson, 1989].

We found that the average cycle length was 28.4 days, fitting well within the range reported for cercopithecoids [ 22.4-39.6 days: e.g. Bettinger et al., 1995; Harris \& Monfort, 2006; partially reviewed in Martin, 2007], but slightly longer in comparison with most colobines [22.4-27.0 days: e.g. He et al., 2001; Heistermann et al., 1995, 2001b, 2004; Table I]. As in other primate species [Heistermann et al., 2001b; van Schaik et al., 2000], the length of the follicular phase was more variable than that of the luteal phase [Lasley \& Benirschke, 1994], and extended cycle lengths were the result of elongated follicular phases. Factors, such as female nutrition, are known to impact primate ovulation [Ellison, 2003] and may have been an important variable influencing cycle length in this population. For instance, cycle lengths estimated from patterns of receptive behavior indicate that Hanuman langur females at the unprovisioned site of Ramnagar have 
Reproductive Traits of Phayre's Leaf Monkey / 1079

TABLE I. Comparative Data on Menstrual Cycle Parameters in Colobines

\begin{tabular}{|c|c|c|c|c|c|c|c|c|c|c|}
\hline \multirow[b]{2}{*}{ Species } & \multirow[b]{2}{*}{$\mathrm{C} / \mathrm{W}$} & \multirow[b]{2}{*}{ Method } & \multirow[b]{2}{*}{$N$} & \multicolumn{2}{|c|}{ Cycle (days) } & \multicolumn{2}{|c|}{ Follicular (days) } & \multicolumn{2}{|c|}{ Luteal (days) } & \multirow[b]{2}{*}{ Source } \\
\hline & & & & Mean & $\mathrm{SE}$ & Mean & $\mathrm{SE}$ & Mean & $\mathrm{SE}$ & \\
\hline Colobus guereza & $\mathrm{W}$ & $\mathrm{H}$ & 6 & 22.4 & 1.6 & NA & NA & NA & NA & Harris and Monfort [2006] \\
\hline Pygathrix nemaeus & $\mathrm{C}$ & $\mathrm{H}$ & $5-9$ & 26.4 & 0.8 & 13.1 & 1.0 & 14.8 & 0.5 & Heistermann et al. [2004] \\
\hline \multirow[t]{2}{*}{ Rhinopithecus bieti } & $\mathrm{C}$ & $\mathrm{H}$ & 3 & 23.6 & 2.0 & 13.2 & 1.0 & 11.5 & 0.7 & He et al. [2001] \\
\hline & $\mathrm{C}$ & M & 10 & 26.1 & 0.5 & & & & & Weizhi et al. [1998] \\
\hline \multirow[t]{3}{*}{ Semnopithecus entellus } & $\mathrm{C}$ & $\mathrm{H}$ & 7 & 25.0 & 2.1 & 12.1 & 2.1 & 12.9 & 0.3 & Heistermann et al. ]1995] \\
\hline & $\mathrm{W}$ & $\mathrm{H}$ & 6 & 27.0 & 1.9 & 12.8 & 1.5 & 14.2 & 1.1 & Heistermann et al. [2001b] \\
\hline & $\mathrm{W}^{\mathrm{a}}$ & M & 113 & 24.2 & 2.3 & & & & & Sommer et al. [1992] \\
\hline $\begin{array}{l}\text { Trachypithecus phayrei } \\
\text { crepusculus }\end{array}$ & $\mathrm{W}$ & $\mathrm{H}$ & $10-14$ & 28.4 & 1.6 & 15.4 & 1.3 & 12.5 & 0.4 & This study \\
\hline
\end{tabular}

( $\mathrm{C}=$ captive; $\mathrm{W}=$ wild; $\mathrm{H}=$ hormone based; $\mathrm{M}=$ menstruation based). Data were selected from sources that used nonbehavioral markers (hormones or menstruation) for assessing cycle length.

${ }^{\text {a }}$ Data derived from provisioned population.

longer cycle lengths compared with those at the provisioned site of Jodhpur [Borries et al., 2001].

The 205-day gestation length found in this study fits within the higher end of the range for colobines [close to the upper 95\% confidence limit of Asian colobines: Borries et al., in review; Jin et al., 2009], but is considerably longer than what is expected for other cercopithecoids [Martin, 2007]. Although there has been a wide range of gestation lengths reported for colobines [e.g. C. guereza, 158 days: Harris \& Monfort, 2006; Trachypithecus cristatus, 194.6 days: Shelmidine et al., 2009; S. entellus, 211.6 days: Ziegler et al., 2000], a recent review has found that within Asian cercopithecoids, colobines as a group have gestation lengths that are $18 \%$ longer relative to cercopithecines [specifically, macaques: Borries et al., in review]. Two suggested explanations for this phylogenetic difference include lower maternal transfer of nutrients during gestation [Martin, 1996] and greater prenatal investment in dental development [Godfrey et al., 2003], both associated with a folivorous diet common to colobines. The fact that the gestation length for Phayre's leaf monkeys still remains long in comparison to other colobines suggests that as with cycle length, nutritional factors may have influenced the length of pregnancy. Although gestation length is thought to be relatively constant, an earlier study on Hanuman langurs [Borries et al., 2001] found that gestation was longer in an unprovisioned relative to a provisioned population, suggesting that nutritional deficits may indeed influence the length of pregnancy.

In conclusion, our study provides the first data on the reproductive characteristics of Phayre's leaf monkeys, using fecal steroid monitoring in a wild group. As such, we have extended our knowledge of the reproductive characteristics of cercopithecoids, particularly of the subfamily Colobinae and the genus Trachypithecus. Our biological validation of steroid hormone measurement from feces and our general results on cycling parameters, conception, and pregnancy provide the basis from which we can begin to examine further questions associated with female fertility and behavior, and more generally, reproductive strategies.

\section{ACKNOWLEDGMENTS}

For cooperation and the permission to conduct research at $\mathrm{Phu}$ Khieo Wildlife Sanctuary, we thank the National Research Council of Thailand, the Department of National Parks, Wildlife and Plant Conservation (DNP), and Phu Khieo Wildlife Sanctuary (Kitti Kreetiyutanont, Mongkol Kumsuk, Kanjana Nitaya, and Jarupol Prabnasuk). We are grateful for the support and cooperation given by Naris Bhumpakphan, Wichan Eiadthong (Kasetsart University), and Warren Brockelman (Mahidol University). For help with data collection, we thank our research assistants and sanctuary rangers. For the use of laboratory space, we thank Barbara Durrant and Gregory Fetter at CRES. This study was financially supported by the National Science Foundation (BCS-0542035 to A. Koenig and C.B.; BCS-0452635 to C.B. and A.L.), the Leakey Foundation (to A.L.), the American Society of Primatologists (to A.L.), the Zoological Society of San Diego (to N.M.C. and A.L.), and the University of Michigan (J.C.B.). The research in Thailand was approved by IACUC Stony Brook University (IDs: 20041120 to 20061120) and complied with the current laws of Thailand and the United States. Special thanks to Thore Bergman, Bill Lasley, Diane Doran-Sheehy, Andreas Koenig, and two anonymous reviewers for their valuable comments on the article.

\section{REFERENCES}

Alberts SC, Hollister-Smith JA, Mututua RS, Sayialel SN, Muruthi PM, Warutere JK, Altmann J. 2005. Seasonality 
and long-term change in a Savanna environment. In: Brockman DK, van Schaik CP, editors. Seasonality in primates: studies of living and extinct human and nonhuman primates. New York: Cambridge University Press. p 157-195.

Aujard F, Heistermann M, Thierry B, Hodges JK. 1998. Functional significance of behavioral, morphological, and endocrine correlates across the ovarian cycle in semifree ranging female Tonkean macaques. American Journal of Primatology 46:285-309.

Bahr NI, Palme R, Möhle U, Hodges JK, Heistermann M. 2000. Comparative aspects of the metabolism and excretion of cortisol in 3 individual nonhuman primates. General and Comparative Endocrinology 117:427-438.

Barnett DK, Abbott DH. 2003. Reproductive adaptations to a large-brained fetus open a vulnerability to anovulation similar to polycystic ovary syndrome. American Journal of Human Biology 15:296-319.

Beehner JC. 2003. Female behavior and reproductive success in a hybrid baboon troop (Papio hamadryas hamadryas $\times$ Papio hamadryas anubis) [Dissertation]. Saint Louis, MO: Washington University. 289p. Available from: University Microfilms, Ann Arbor; AAT 3117052.

Beehner JC, Nguyen N, Wango EO, Alberts SC, Altmann J. 2006. The endocrinology of pregnancy and fetal loss in wild baboons. Hormones and Behavior 49:688-699.

Bentley-Condit VK, Smith EO. 1997. Female reproductive parameters of Tana River yellow baboons. International Journal of Primatology 18:581-596.

Bettinger T, Wallis J, Morris A. 1995. Reproductive parameters of mandrills at the Tulsa Zoo. Zoo Biology 14: 114-121.

Borries C, Koenig A, Winkler P. 2001. Variation of life history traits and mating patterns in female langur monkeys (Semnopithecus entellus). Behavioral Ecology and Sociobiology 50:391-402.

Borries C, Larney E, Lu A, Ossi K, Koenig A. 2008. Costs of group size: lower developmental and reproductive rates in larger groups of leaf monkeys. Behavioral Ecology 19: $1186-1191$.

Borries C, Lu A, Ossi-Lupo K, Larney E, Koenig A. in review. Primate life histories and dietary adaptations: a comparison of Asian colobines and macaques. American Journal of Physical Anthropology.

Brauch K, Pfefferle D, Hodges K, Möhle U, Fischer J, Heistermann M. 2007. Female sexual behavior and sexual swelling size as potential cues for males to discern the female fertile phase in free-ranging Barbary macaques (Macaca sylvanus) of Gibraltar. Hormones and Behavior 52:375-383.

Cockrem JF. 2005. Conservation and behavioral neuroendocrinology. Hormones and Behavior 48:492-501.

Dailey RA, Neill JD. 1981. Seasonal variation in reproductive hormones of rhesus monkeys: Anovulatory and short luteal phase menstrual cycles. Biology of Reproduction 25: 560-567.

Deschner T, Heistermann M, Hodges K, Boesch C. 2004. Female sexual swelling size, timing of ovulation, and male behavior in wild West African chimpanzees. Hormones and Behavior 46:204-215.

Dixon WJ, Massey FJ. 1969. Introduction to statistical analysis. New York: McGraw-Hill. 638p.

Ellison PT. 2003. Energetics and reproductive effort. American Journal of Human Biology 15:342-351.

Emery MA, Whitten PL. 2003. Size of sexual swellings reflects ovarian function in chimpanzees (Pan troglodytes). Behavioral Ecology and Sociobiology 54:340-351.

Emery Thompson M, Wilson ML, Gobbo G, Muller MN, Pusey AE. 2008. Hyperprogesteronemia in response to Vitex fischeri consumption in wild chimpanzees (Pan troglodytes schweinfurthii). American Journal of Primatology 70: 1064-1071.

Engelhardt A, Hodges JK, Niemitz C, Heistermann M. 2005. Female sexual behavior, but not sex skin swelling, reliably indicates the timing of the fertile phase in wild long-tailed macaques (Macaca fascicularis). Hormones and Behavior 47:195-204

Engelhardt A, Hodges JK, Heistermann M. 2007. Postconception mating in wild long-tailed macaques (Macaca fascicularis): characterization, endocrine correlates and functional significance. Hormones and Behavior 51:3-10.

Fujita S, Sugiura H, Mitsunaga F, Shimizu K. 2004. Hormone profiles and reproductive characteristics in wild female Japanese macaques (Macaca fuscata). American Journal of Primatology 64:367-375.

Garey J. 1991. Acacia flowers from wild vervet diets are reproductive stimulators. American Journal of Primatology 24:102-103.

Gesquiere LR, Wango EO, Alberts SC, Altmann J. 2007. Mechanisms of sexual selection: sexual swellings and estrogen concentrations as fertility indicators and cues for male consort decisions in wild baboons. Hormones and Behavior 51:114-125.

Godfrey LL, Samonds KE, Jungers WL, Sutherland MR. 2003. Dental development and primate life histories. In: Kappeler PM, Pereira ME, editors. Primate life histories and socioecology. Cambridge: Cambridge University Press. p 177-203.

Graham L, Schwarzenberger F, Mostl E, Galama W, Savage A. 2001. A versatile enzyme immunoassay for the determination of progestogens in feces and serum. Zoo Biology 20:227-236.

Grieger DM, Scarborough R, Deavila DM, Johnson HE, Reeves JJ. 1990. Active immunization of beef heifers against luteinizing hormone. 3. Evaluation of dose and longevity. Journal of Animal Science 68:3755-3764.

Harris TR, Monfort SL. 2006. Mating behavior and endocrine profiles of wild black and white Colobus monkeys (Colobus guereza): toward an understanding of their life history and mating system. American Journal of Primatology 68:383-396.

Harvey PH, Martin RD, Clutton-Brock TH. 1987. Life histories in comparative perspective. In: Smuts BB, Cheney DL, Seyfarth RM, Wrangham RW, Struhsaker TT, editors. Primate societies. Chicago: University of Chicago Press. p 181-196.

He YM, Pei YJ, Zou RJ, Ji WZ. 2001. Changes of urinary steroid conjugates and gonadotropin excretion in the menstrual cycle and pregnancy in the Yunnan snub-nosed monkey (Rhinopithecus bieti). American Journal of Primatology 55:223-232.

Heistermann M, Finke M, Hodges JK. 1995. Assessment of female reproductive status in captive-housed Hanuman langurs (Presbytis entellus) by measurement of urinary and fecal steroid excretion patterns. American Journal of Primatology 37:275-284.

Heistermann M, Uhrigshardt J, Husung A, Kaumanns W, Hodges JK. 2001a. Measurement of faecal steroid metabolites in the lion-tailed macaque (Macaca silenus): a noninvasive tool for assessing female ovarian function. Primate Report 59:27-42.

Heistermann M, Ziegler T, van Schaik CP, Launhardt K, Winkler P, Hodges JK. 2001b. Loss of oestrus, concealed ovulation and paternity confusion in free-ranging Hanuman langurs. Proceedings of the Royal Society of London B 268:2445-2451.

Heistermann M, Ademmer C, Kaumanns W. 2004. Ovarian cycle and effect of social changes on adrenal and ovarian function in Pygathrix nemaeus. International Journal of Primatology 25:689-708.

Higham JP, Ross C, Warren Y, Heistermann M, MacLarnon AM. 2007. Reduced reproductive function in wild baboons 
(Papio hamadryas anubis) related to natural consumption of the African black plum (Vitex doniana). Hormones and Behavior 52:384-390.

Higham JP, Heistermann M, Ross C, Semple S, MacLarnon A. 2008a. The timing of ovulation with respect to sexual swelling detumescence in wild olive baboons. Primates 49:295-299.

Higham JP, MacLarnon AM, Ross C, Heistermann M, Semple S. 2008b. Baboon sexual swellings: information content of size and color. Hormones and Behavior 53:452-462.

Higham JP, Warren Y, Adanu J, Umaru BN, MacLarnon AM, Sommer V, Ross C. 2009. Living on the edge: life-history of olive baboons at Gashaka-Gumti National Park, Nigeria. American Journal of Primatology 71:293-304.

Holm S. 1979. A simple sequentially rejective multiple test procedure. Scandinavian Journal of Statistics 6:65-70.

Hrdy SB. 1977. The langurs of Abu: female and male strategies of reproduction. Cambridge: Harvard University Press. 361p.

Jin T, Wang D, Zhao Q, Yin L, Qin D, Ran W, Pan W. 2009. Reproductive parameters of wild Trachypithecus leucocephalus: seasonality, infant mortality and interbirth interval. American Journal of Primatology 71:1-9.

Johnson MH. 2007. Essential reproduction. Massachusetts: Blackwell. 316p.

Koenig A, Borries C, Chalise MK, Winkler P. 1997. Ecology, nutrition, and timing of reproductive events in an Asian primate, the Hanuman langur (Presbytis entellus). Journal of Zoology, London 243:215-235.

Lasley B, Benirschke K. 1994. Strategies of ovarian function of importance to gynecologic investigations. Journal of the Society for Gynecologic Investigation 1:247-255.

Maestripieri D. 1999. Changes in social behavior and their hormonal correlates during pregnancy in pig-tailed macaques. International Journal of Primatology 20:707-718.

Martin RD. 1996. Scaling the mammalian brain: the maternal energy hypothesis. News Physiology Science 11:149-156.

Martin RD. 2007. The evolution of human reproduction: a primatological perspective. Yearbook of Physical Anthropology 50:59-84.

Martin RD, MacLarnon AM. 1985. Gestation period, neonatal size and maternal investment in placental mammals. Nature 313:220-223.

Möhle U, Heistermann M, Dittami J, Reinberg V, Hodges JK. 2005. Patterns of anogenital swelling size and their endocrine correlates during ovulatory cycles and early pregnancy in free-ranging Barbary macaques (Macaca sylvanus) of Gibraltar. American Journal of Primatology 66:351-368.

Molskness TA, Hess DL, Maginnis GM, Wright JW, Fanton JW, Stouffer RL. 2007. Characteristics and regulation of the ovarian cycle in vervet monkeys (Chlorocebus aethiops). American Journal of Primatology 69:890-900.

North LA, Harder JD. 2008. Characterization of the estrous cycle and assessment of reproductive status in Matschie's tree kangaroo (Dendrolagus matschiei) with fecal progestin profiles. General and Comparative Endocrinology 156:173-180.

Nunn CL. 1999. The evolution of exaggerated sexual swellings in primates and the graded-signal hypothesis. Animal Behaviour 58:229-246.
Ostner J, Heistermann M. 2003. Endocrine characterization of female reproductive status in wild redfronted lemurs (Eulemur fulvus rufus). General and Comparative Endocrinology 131:274-283.

Perez LE, Czekala NM, Weisenseel KA, Lasley BL. 1988. Excretion of radiolabeled estradiol metabolites in the slow loris (Nycticebus coucang). American Journal of Primatology 16:321-330.

Ramirez SM, Bardi M, French JA, Brent L. 2004. Hormonal correlates of changes in interest in unrelated infants across the peripartum period in female baboons (Papio hamadryas anubis sp.). Hormones and Behavior 46:520-528.

Shelmidine N, Borries C, McCann C. 2009. Patterns of reproduction in Malayan silvered leaf monkeys at the Bronx Zoo. American Journal of Primatology 71:852-859.

Shimizu K, Udono T, Tanaka C, Narushima E, Yoshihara M, Takeda M, Tanahashi A, van Elsackar L, Hayashi M, Takenaka O. 2003. Comparative study of urinary reproductive hormones in great apes. Primates 44:183-190.

Smuts BB, Nicolson N. 1989. Reproduction in wild female olive baboons. American Journal of Primatology 19:229-246.

Sokal RR, Rohlf FJ. 1995. Biometry, 3rd ed. New York: W.H. Freeman and Company. 887p.

Sommer V, Srivastava A, Borries C. 1992. Cycles, sexuality, and conception in free-ranging langurs (Presbytis entellus). American Journal of Primatology 28:1-27.

Strier KB, Ziegler TE. 1997. Behavioral and endocrine characteristics of the reproductive cycle in wild muriqui monkeys, Brachyteles arachnoides. American Journal of Primatology 42:299-310.

van Schaik CP, Hodges JK, Nunn CL. 2000. Paternity confusion and the ovarian cycles of female primates. In: van Schaik $\mathrm{CP}$, Janson $\mathrm{CH}$, editors. Infanticide by males and its implications. Cambridge: Cambridge University Press. p 361-387.

Wallen K. 2001. Sex and context: Hormones and primate sexual motivation. Hormones and Behavior 40:339-357.

Wasser SK, Hunt KE, Brown JL, Cooper K, Crockett CM, Bechert U, Millspaugh JJ, Larson S, Monfort SL. 2000. A generalized fecal glucocorticoid assay for use in a diverse array of nondomestic mammalian and avian species. General and Comparative Endocrinology 120:260-275.

Wasser SK, Monfort SL, Southers J, Wildt DE. 1994. Excretion rates and metabolites of oestradiol and progesterone in baboon (Papio cynocephalus cynocephalus) faeces. Journal of Reproduction and Fertility 101:213-220.

Weizhi J, Rujin Z, Enyuan S, Hongwu Z, Shangchuan Y, Baoping T. 1998. Maintenance and breeding of Yunnan snub-nosed monkeys (Rhinopithecus bieti) in captivity. In: Jablonski NG, editor. The natural history of the Doucs and snub-nosed monkeys. London: World Scientific. p 323-333.

Yan C, Jiang ZG. 2006. Does estradiol modulate sexual solicitations in female Rhinopithecus roxellana? International Journal of Primatology 27:1171-1186.

Ziegler T, Hodges JK, Winkler P, Heistermann M. 2000. Hormonal correlates of reproductive seasonality in wild female Hanuman langurs (Presbytis entellus). American Journal of Primatology 51:119-134. 